\title{
Maternal Use of Marijuana during Pregnancy and Lactation: Implications for Infant and Child Development and Their Well-Being
}

\author{
T. Allen Merritt ${ }^{1 *}$, Wilkinson $\mathbf{B}^{2}$ and Chervenak $\mathrm{C}^{3}$ \\ ${ }^{1}$ Department of Pediatrics, Loma Linda University School of Medicine, USA \\ ${ }^{2}$ Medical Student, Western University of Health Sciences, USA \\ ${ }^{3}$ Medical Director, ABC House, Albany, Oregon 97321
}

Submission: September 24, 2016; Published: November 04, 2016

*Corresponding author: T. Allen Merritt, M.D., MHA, Department of Pediatrics, Loma Linda University School of Medicine, Loma Linda, Ca and Western University of Health Sciences, Lebanon, Oregon, USA, Email: tamerritt@llu.edu

\begin{abstract}
Legalization of marijuana for recreational use has increased the overall consumption of Cannabis spp. in Alaska, Colorado, Washington, and Oregon. We review the evidence regarding the impact of marijuana use during pregnancy and breastfeeding including evidence for adverse effects on infant and child neurodevelopment maturation and cognitive function. Based on animal and limited human studies of fetal brain tissue epigenetic effects of marijuana exposure during pregnancy on brain development have been documented. The recommendations from several professional organizations which advocate for the avoidance of marijuana by mothers during pregnancy, and the potential for adverse effects during breastfeeding, are reviewed. Studies find a positive association between parental drug use and child maltreatment. States with recreational marijuana have enacted laws regarding use of marijuana while driving a motor vehicle. There are existing laws regarding child endangerment in the context of driving under the influence. Legal marijuana use by parents is still in its infancy and questions of children endangerment have not been yet been fully answered. As more states legalize marijuana for recreational use the impact of prenatal exposure to cannabis and infant exposure, both Second-hand Smoke and through ingestion of contaminated breast milk during lactation needs to be carefully documented with a focus on the relationship between marijuana consumption and outcomes of pregnancy including infant and child psychomotor and cognitive development. In Colorado more than twice as many infants 1-24 months hospitalized for bronchiolitis in 2015 were found to have THC in their urine in after legalization indicating that recreational use contributed to secondhand marijuana smoke exposure in theses infants and thus, a growing health concern.

Parenting skills and capacities may be altered with chronic marijuana use and rates of child abuse and endangerment will require systematic evaluation with broader use of marijuana after legalization. Broader availability of edible marijuana and its distillates that can be consumed by children pose significant health risks to children increasing healthcare utilization.
\end{abstract}

Keywords: Marijuana; $\Delta 9$ tetrahydrocannabinol; Pregnancy; Breastfeeding, Child development; Parenting skills; Child Maltreatment; Child Poisonings

\section{Introduction}

Marijuana (Cannabis spp.) is among the most widely used psychoactive drug in the U.S.A. among women during their reproductive years. In a large sample of marijuana users among women of reproductive age $(n=17,934)$ in 2013 , nearly daily use was reported by $16.2 \%$ pregnant and $12.8 \%$ non-pregnant women, with $18.1 \%$ of pregnant and $11.4 \%$ non-pregnant marijuana using women meeting the criteria for abuse and/or dependence [1]. Metz \& Stickrath [2] reported a prevalence of marijuana use during pregnancy and lactation ranges from 2-27\% depending on the population and method of detection [2]. Twentytwo U.S. states and the District of Columbia have authorized use of "medical marijuana," however, Alaska, Colorado, Washington, and Oregon have legalized the "recreational use" of marijuana for adults (21 years or older). While under federal law marijuana use remains illegal (Title 21 United State Code Controlled Substances Act) in 2013, an estimated 19.8 million individuals reported using marijuana within the previous month. Legalization of recreational 
and medical marijuana use across the United States heightens the potential for increased use among pregnant and lactating women, and will increase the number of fetuses exposed to marijuana in utero and may increase the number of women who use marijuana while breastfeeding.

$\Delta$-9tetrahydro-cannabinol (THC) is one of many cannabinoids such as cannabidiol, cannabinol, tetrahydrocannabivarin, and cannabiogerol known to have pharmacologic effects in the marijuana plant. These phytocannabinoids are distinct from endocannabinoids that are endogenously produced from arachidonic acid derivatives. Endocannabinoids modulate regulation of movement, memory, appetite, thermoregulation, pain, and immunity through cannabinoid receptors present throughout the body. The endogenous cannabinoid system plays a role in maintaining and regulating early pregnancy and CB1 receptors are present in placental tissue. Over-stimulation of CB1 receptors in the placenta can impair fetal growth by inhibiting cytotrophoblastic proliferation. The endocannabinoid system plays a major role in embryo survival and brain development. Endogenous cannabinoids and cannabinoid receptors in the developing fetal brain may be detected from the earliest stages of embryogenesis and throughout pre-and-postnatal development. CB1 and CB2 receptor mRNA have been detected as early as the preimplantation period in the embryo and in the developing brain prenatal and postnatally [3]. CB1 receptors are identifiable in brain white matter and in regions of cell proliferation and are involved in critical neuronal proliferation, migration, and synaptogenesis. Endocannabinoids have been shown to regulate neural progenitor cell differentiation and survival. The lipophilic properties of the cannabinoids allow them to readily cross many types of cell barriers, including the blood-brain barrier and placental membranes.

Cannabis and its metabolites have been detected in many human tissues, including the placenta, amniotic fluid, many fetal tissues, and in breast milk. The concentrations of cannabis and its metabolites can be several times higher in fetal tissue than in the maternal plasma depending on the potency, duration, and method of maternal cannabis consumption. Between 1993 and 2008 [4] the mean concentrations of THC in marijuana increased from $3.4 \%$ to $8.8 \%$, and recent reports through 2012 reveal concentrations of THC in leaf marijuana up to $12 \%$, and various concentrated preparations and extract s of THC (e.g. "hash oil") containing over $30 \%$ THC [5]. Recent reports have found ammonia levels to be 20 times higher in marijuana smoke than tobacco smoke, while hydrogen cyanide, nitric oxide and certain aromatic amines occurred at levels three to five-fold higher in marijuana compared to tobacco smoke [6].

\section{Marijuana Use during Pregnancy}

Cannabis use during pregnancy has the potential to affect fetal development. Further the use of THC while breastfeeding during the newborn period may have adverse effects on the newborn. It has been proposed that exposure to cannabis and its metabolites leads to stimulation of the endogenous cannabinoid system that may then disrupt the ontogeny of endogenous endocannabinoid signaling and interfere with synaptogenesis and the proliferation of neural connections [7]. In addition, there is evidence that cannabis may also disrupt developing neutrotransmitter systems such as dopaminergic neurons that are expressed early in the developing brain and exert trophic effects on neurons. Cannabis exposure during pregnancy may down regulate tyrosine hydroxylase activity, the rate-limiting enzyme for dopamine synthesis that has the potential to impact the maturation of dopaminergic target cells. Disturbances in dopamine function have been associated with an increased risk of neuropsychiatric disorders, such as depression, schizophrenia, and drug dependence [7]. Prenatal exposure to THC has been noted to alter endogenous encephalin precursors and the expression of opioid and serotonin receptors in animal models [8].

$\Delta 9$-THC inhibits gonadotropin, prolactin, growth hormone, and thyroid-stimulating hormone release and stimulates the release of $\mathrm{ACTH}$, thereby altering breast milk production in lactating women [8]. $\Delta 9$-THC is present in human milk up to eight times that of maternal plasma levels, and metabolites are found in infant meconium and feces, indicating that THC is absorbed and metabolized by the fetus and infant [9]. It is rapidly distributed to the brain and adipose tissue and stored in fat tissues for weeks to months. Its half-life ranges from 25-57 hours and THC may be present in the urine for 2-3 weeks making it impossible to determine those who are occasional versus chronic users at the time of delivery by urine toxicology screening [9].

Inhalation of marijuana smoke includes the sustained inhalation of unfiltered marijuana smoke as opposed to tidal inhalation generally used when smoking tobacco and exhalation of marijuana smoke poses similar threats to infant health as secondhand tobacco smoke that have been associated with increased rates of respiratory illnesses during childhood including asthma, bronchitis and pneumonia, and more frequent ear infections [10].

Data on the effect of cannabis use in pregnancy on different birth outcomes have not found an increased risk of spontaneous abortions; however, recent studies suggest that cannabis use during pregnancy is associated with stillbirth, preterm labor, intrauterine growth restriction, and in some studies an increase in birth defects. The National Institute of Child Health and Human Development Stillbirth Collaborative Research Network reported that cannabis use is associated with increased risk of stillbirth [odds ratio 2.34; 95\% confidence interval (CI) 1.13-4.811] [11]. After controlling for tobacco smoking, alcohol consumption, and the use of other drugs, Mannes and coworkers found that cannabis use during pregnancy was associated with low birth weight [odds ratio 1.7; 95\% CI 1.3-2.2], preterm labor [odds ratio 1.5; 95\% CI 1.1-1.9] small for gestation age by birth weight [odds ratio 2.2; 
95\% CI 1.8-2.7), and neonatal intensive care unit admission [odds ratio 2.0; $95 \% \mathrm{Cl} 1.7-2.4$ ] [12]. The Generation $\mathrm{R}$ study from the Netherlands [13] enrolled over 7,000 mothers and fetal growth was followed using ultrasound during all trimesters and the early newborn period. Maternal cannabis use during pregnancy was associated with fetal growth restriction during the second and third trimesters and infants were delivered with lower birth weights with cannabis-exposed infants having a growth reduction of $-14.4 \mathrm{gm} /$ week (95\%CI -22.9-5.9, p>.001) and reduced head circumference of $-.21 \mathrm{~cm} /$ week $(95 \% \mathrm{CI}-0.42-0.02 \mathrm{~cm})$. Infants of marijuana users had more pronounced fetal growth restriction and greater than those associated with maternal tobacco smoking. Rates of birth defects have been reported to be higher than expected among women using marijuana during pregnancy (obstructive genitourinary defects, polydactyly, syndactyly, and upper limb reduction deformities [14]; however, recent studies have found no increased risk for birth defects $[15,16]$.

Disturbances in neurobehavioral function among infants exposed to THC such as exaggerated and prolonged startle reflex, increased hand-mouth behavior, high-pitched cry, poor habituation and disturbances in infant sleep-wake cycles have been reported among babies whose mother revealed cannabis use during the third trimester [3,17]. Evidence suggests that in utero cannabis exposure has an adverse impact on longer-term neurodevelopment outcomes of exposed infants [18]. Reports of delayed acquisition of visual-perceptual tasks and language skills, increased levels of aggression, poor attention skills, deficits in reading, spelling, and problem solving skills and tasks requiring visual memory, analysis, and integration have been reported in cannabis-exposed infants during later childhood $[19,20]$. Poorer school performance, as early as 6 years, appears to persist beyond late childhood. Moderate cognitive deficits after marijuana use during pregnancy are found in infants at 4 years of age [20]. There is moderate evidence for an association with decreased IQ scores, reduced cognitive function, depression and decreased academic ability in adolescence [21-33]. First trimester marijuana exposure is also associated with poorer reading and composition scores on the Welscher Individual Achievement Test at 14 years of age [24]. Evidence exists for an association with attention problems among children in pre-school, and childhood [25-27], and mixed evidence for an association with newborn behavioral issues [2829] after marijuana use during pregnancy. Limited data exist for an association with increased depression symptoms and delinquent behaviors with lower 'executive function' for 9-12 year-olds after their exposure to marijuana in utero [28-30]. Mothers who smoked marijuana during pregnancy also describe their children as more impulsive or hyperactive [31].

\section{Marijuana and Breastfeeding}

Marijuana use during breastfeeding has been associated with delayed infant motor development at one year. Infant lethargy, less frequent and shorter feedings at breast, and high milk-plasma ratios of THC have been reported in "heavy" marijuana users [32]. $\Delta 9$ THC is present in human milk up is up to eight times higher than maternal plasma levels, and THC or its metabolites are found in infant stools, indicating that THC is absorbed and metabolized by the infant [33]. $\Delta 9 \mathrm{THC}$ is highly lipid soluble and is distributed to the brain and adipose tissue where it is stored for weeks to months. Based on studies in lactating monkeys receiving $2 \mathrm{mg}$ of THC daily, $0.2 \%$ of the maternal dose was measured in breast milk over a 24 hour period [34]. Friguis and coworkers document that infants ingest approximately $0.8 \%$ of the maternal dose $/ \mathrm{kg}$ from one "joint" during one breastfeeding and infant may breast feed up 8 to 10 times daily [35]. The half-life is 20-57 hours and stays in the infant's urine for up to 2 to 3 weeks making it difficult to determine an occasional versus a chronic marijuana user at the time of delivery by urine toxicology studies alone [36]. Marijuana exposure from maternal milk during the first month after birth was associated with a decrease in motor development at one year; however, there was no association between marijuana exposure during the third month after birth and motor development $[37,38]$. The potency of $\Delta 9$ THC in cannabis currently available for medicinal or recreational use is many times greater than that used in previous studies [39]. Ongoing evaluation of the impact on infant development in breast fed infants exposed to currently available marijuana potencies are warranted, especially in mothers using moderate or heavy amounts of marijuana. Miller has summarized effects of marijuana smoking and breastfeeding in infants as increased tremors, poor sucking reflex, decreased feeding time, slower weight gain, changes in visual responses, and delayed motor development. She stresses that marijuana use while breastfeeding is a cause for concern among lactation consultants and medical providers and requires individualized assessment, plan of care, and follow-up of infants exposed to marijuana from breast feeding [40].

The Academy of Breastfeeding Medicine advocates that mothers should be counseled to reduce or eliminate their use of marijuana to avoid exposing their infants to the substances in cannabis and of the possible longer-term adverse neurodevelopmental effects from continued use [41].

\section{These specific recommendations are summarized:}

1. Counsel Mothers who admit to occasional or rare use to avoid further use or reduce their use as much as possible while breastfeeding, advise them regarding long-term neurobehavioral effects, and instruct mothers to avoid direct exposure of their infant to marijuana and its smoke.

2. Counsel mothers found with a positive urine screen for THC to discontinue marijuana use while pregnant and counsel them as to the possible long-term neurodevelopment effects of marijuana exposure.

3. Consideration and counseling be given on the known benefits of breastfeeding versus the potential risks of exposure 
of marijuana on infant development.

4. The lack of long-term follow-up data on infants exposed to varying amounts marijuana via human milk, coupled with concerns over negative neurodevelopment outcomes in children with in utero exposure should prompt extremely careful consideration of the risks versus benefits of breastfeeding in the setting of moderate or chronic marijuana use and that abstinence from any marijuana use is warranted.

The Academy of Breastfeeding Medicine urges caution but also states that data are not strong enough to recommend against breastfeeding with any marijuana use. The American College of Obstetricians and Gynecologists states:"There are insufficient data to evaluate the effects of marijuana use on infants during lactationand breastfeeding, and in the absence of such data, marijuana use is discouraged." [42]. The American Academy of Pediatrics recommends that women using marijuana not breastfeed their infants [43].

Noteworthy, pharmacologic preparations of $\Delta 9$ THC such as Marinol@ (Dronabinol) are not recommended for nursing mothers by the manufacturer [44], and the packet insert of Cesamet ${ }^{\circledR}$ (nabilone) also recommends against use by nursing mothers [45].

\section{Marijuana and Epigenetic Modifications}

Epigenetic modifications of histones play a major role in epigenetic regulation; histone acetylation, methylation and phosphorylation have been implicated in gene regulation and neurobiological disturbances related to drug use during pregnancy [46]. Exposure to cannabinoids during one generation has been implicated in epigenetic changes in offspring primarily in animal studies, although data from humans is emerging. After prenatal cannabinoid exposure, rats self-administered more heroin, particularly when stressed, revealing greater opiate reward behaviors than unexposed rats [47]. Studies of prenatal THC exposure in rats have found disturbances in histone modification in the adult brain, and a reduction in mRNA transcript levels in the nucleus accumbens in fetal tissue of cannabis exposed women suggesting that maternal cannabis use alters the developmental regulation of mesolimbic dopamine receptors [48]. Maternal THC exposure during pregnancy has been associated with fetal changes in mRNA expression of cannabinoid, dopamine, and glutamatergic receptor genes in the dorsal striatum key neuronal pathways mediating compulsive behaviors and reward sensitivities [49]. These findings suggest that parental germline THC exposure leads to cross-generational disturbances in the dorsal striatal synaptic plasticity. Paternal marijuana use has also been reported in two-case controlled studies to increase the risk of membranous ventricular septal defects in their children [50,51].

\section{Marijuana and Public Health Agencies}

Recent reports by public health authorities in Colorado [52], Oregon [53] and Washington [54,55] have summarized peerreviewed evidence regarding maternal marijuana use and health effects on infants and conclude the following:

1. THC is present in the breast milk of women who use marijuana and can be detected after recent use.

2. THC is absorbed and metabolized by infants ingesting breast milk of mothers who use marijuana. In one feeding, the exposed infant would intake $0.8 \%$ of the weight adjusted maternal intake of one joint and exposed infants will excrete THC in their urine for 2-3 weeks [53].

3. Although the Colorado report states that there is mixed evidence for association with motor development in exposed infants, the Oregon report describes decreased motor development and poor sucking in infants whose mothers use marijuana.

4. A Washington State document summarizes that "the main psychoactive component in marijuana (THC) passes from mother to child during pregnancy and through breast milk" [54]. Emerging research also suggests there is an association between marijuana and decreased fetal growth, development and executive functioning and mood disorders in children. THC stays in the body of mothers and babies for a long time can test positive for THC weeks after being exposed. Babies exposed to THC can having problems with breastfeeding.

5. This report also states "parental substance use doesn't necessarily result in child harm or neglect" [55]. If a mandated reporter has reasonable cause to believe that a child has suffered child abuse/neglect they are required to report. New language has been added: "If you (a mandated reporter) believe that a parent's substance use/abuse is causing child abuse or neglect, consult Child Protective Service. This includes the use of marijuana and alcohol."

\section{Marijuana and Parenting Skills}

An issue yet to be resolved by Public Health Authorities or Child Protection Services agencies whose legislative mandate is to protect the care and welfare of children is the degree to which "parenting skills" may be impaired by marijuana use, and what level of marijuana use constitutes child endangerment [56]. In a community hospital in Oregon that universally screens women for drugs of abuse when admitted for labor and delivery found $11.8 \%$ with positive urine screens for THC in 2014 and 2015 (prior to legalization), and 18\%in the first 6 months in 2016 after legalization. (data on file). Prenatal substance exposure is associated with a 2 to 3 times increased risk of subsequent child maltreatment [57]. Among multiple risk factors identified in research literature, family substance abuse is the strongest predictor of child neglect [58].

In a telephone survey of 3,023 respondents living in 50 midsize California cities, individual level data on marijuana use and abusive and neglectful parenting were collected. Within one year of the survey, current marijuana users self-identified an increased frequency of child physical abuse but did not self-report physical 
or supervisory neglect after controlling for parent income, employment and education. Noteworthy, the density of medical marijuana dispensaries and delivery services was positively related to frequency of child physical abuse [59]. Concern has also been expressed because of the wider availability of marijuana "edibles", often packaged in colors and preparations attractive to children. Parents who inadequately supervise and/or underestimate the impact of marijuana ingestion place their children at significant risk of harm by allowing access to marijuana [60].

Present evidence suggests that marijuana use during pregnancy has adverse effects on fetal development and neurobehavioral effects from the neonatal period through adolescence. However, limited information regarding the impact of marijuana use exclusively during breastfeeding is insufficient to verify that use of marijuana solely during breastfeeding adversely affects newborns. Driving after marijuana use may impair drivers and increase motor vehicle collision risk [60]. Driving with a child in the car, while under the influence of marijuana or other drugs or alcohol is considered child endangerment. Ongoing surveillance will be necessary to determine whether the legalization of marijuana for recreational use results in greater numbers of infants and children being endangered by parents' marijuana use associated with driving under the influence and/or through the increase in the prevalence of neglectful parenting.

Brook and coworkers [61] assessed effects of the interrelationship of mothers' and fathers' tobacco and marijuana use with personality attributes and child-rearing behaviors. In the longitudinal study, 258 parents were seen four times over a 13 year period during their early teens into adulthood. Their findings suggested that parent protective personality characteristics were offset by substance use and resulted in less adequate parenting skills. In a recent study reported from Colorado, Thurstone et al. [62] found that among parents using medical marijuana 6/11 parents reported that using marijuana helped them to be calmer with their children and to manage difficult emotions related to parenting; however, most parents did not want their children to use marijuana, and therefore they sought alternatives. Accidental ingestion of marijuana by children is a growing concern because of the increased availability of attractive "edible" forms of marijuana such as baked goods, candy and soft drinks, as well as highly concentrated marijuana resins and extracts (i.e., "hash oil").

Among states with the legalization of medical and recreational marijuana, there has been a marked increase in toxic marijuana exposures of young children $[63,64]$. Clinical symptoms among children include stupor, vomiting, and hypotonia [65]. Medical intervention involved multiple tests, procedures, imaging and frequent hospital admission. At Children's Hospital Colorado Regional Poison Control Center, the annual pediatric marijuana cases increased from 2009 to 2015 by $34 \%$, while in the remainder of the U.S. this increase was only $19 \%$, of which $51 \%$ were associated with edible forms of marijuana [66]. In a recent study in Colorado $16 \%$ of children of 1-24 months of age hospitalized for bronchiolitis had been exposed to marijuana smoke as urine samples revealed positive drug screens for THC. In addition, more children were found to be THC positive after legalization (21\%) [68], Furthermore, as more adolescents perceive recreational marijuana use as a "less risky behavior" as evidence by data from Washington State prior to and after legalization of marijuana, this perception of less risk may lead to greater use among women during their early reproductive years [69].

\section{Summary}

Legalization of recreational marijuana use by women 21 years or older (and illegal use by younger women of reproductive age) may have anticipated effects on their children requiring intervention by pediatricians, psychiatrists, teachers, and school counselors. Consideration of the adverse impact of marijuana use during pregnancy on later child cognitive function is critical when evaluating children who have global developmental delay, inattention, impulsivity, hyperactivity, and externalizing behaviors such as mood/anxiety disorders who present in later to pediatricians for behavioral or educational evaluations. Prenatal marijuana exposure has been associated with decreased intellectual development among 4-6 year olds, increased depressive symptoms among 10 year olds, and reduced academic performance and executive function among adolescents. Among risk factors for child neglect, family substance abuse was the strongest predictor of child neglect. Accidental ingestion of marijuana products has been shown to endanger children and greater awareness of the need to test children for THC will be necessary where there is greater access to marijuana and derivative products. Perceptions of less risk of marijuana use among adolescents following legalization may lead to increased use during pregnancy and an even greater impact on fetal and infant and child development.

In peer reviewed published reports regarding the impact of marijuana use during pregnancy and the effects on long-term child development it is important to consider that many of women in these studies (and their children) were exposed to other substances (tobacco, cocaine, alcohol) in addition, to marijuana, and that comparison groups for these studies may have been less than ideal. There is an urgent need for further research using study designs that control for concomitant drug use during pregnancy and lactation, the overall health status of women who use marijuana, and the frequency of its use. Current commercially available marijuana has significantly higher concentrations of THC than those used in previous studies, thus it is conceivable that earlier reports may under estimate the impact of chronic marijuana use during pregnancy on childhood outcomes; however, this is currently unknown. Longitudinal follow-up studies will be essential in acquiring actionable data to reinforce existing public health advisories focused on reducing use of marijuana during pregnancy and lactation. 


\section{Acknowledgement}

Portions of this manuscript were published previously in Neonatology Today, Vol 11, Issue 2, 2016.

\section{References}

1. Ko JY, Farr SL, Tong VT, Creanga AA, Callaghan WM (2015) Prevalence and patterns of marijuana use among pregnant and non-pregnant women of reproductive age. AJOG 213(12): 201.e1-201.e10.

2. Metz T, Stickrath E (2015) Marijuana use in pregnancy and lactation: a review of the evidence. AJOG 213(6): 761-768.

3. Campolongo P, Trezza V, Paalmery M, Trabace L, Cuomo V, et al. (2009) Developmental exposure to cannabinoids causes subtle and enduring neurofunctional alterations. Intern Rev of Neurobio 85: 117-33.

4. El-Sohly MA (2014) Potency monitoring Program quarterly report no 123-reporting period: 09/16/2013-12/13/2013. Oxford University of Mississippi, National Center for Natural Products Research.

5. Mehmedic Z, Chandra S, Slade D, Denham H, Foster S, et al. (2010) Potency trends of $\triangle 9$-THC and other cannabinoids in confiscated cannabis preparations from 1993 to 2008. Forensic Sci 55(5): 12091217.

6. Moir D, Rickert WS, Levasseur G, Larose Y, Maertens R, et al. (2008) A comparison of mainstream and sidestream Marijuana and Tobacco Cigarette Smoke Produced under Two Machine Smoking Conditions. Chem Re Toxicol 21(2): 494-502.

7. Volkow ND, Baler RD, Compton WM, Weiss SRB (2014) Adverse Health Effects of Marijuana Use. N Engl J Med 370 (23): 2219-2227.

8. Jaques SC, Kingsbury A, Henshcke P, Chomchai C, Clews S, et al. (2014) Cannabis, the pregnant woman and her child: weeding out the myths. J. Perinatol 34(6): 417-424.

9. Garry A, Rigourd V, Amirouche A, Fauroux V, Aubry S, et al. (2009) Cannabis And Breastfeeding. J Toxicology.

10. (2014) The Health Consequences Smoking-50 Years of Progress: A Report of the Surgeon General. U.S. Department of Health and Human Services, Atlanta: U.S, Department of Health and Human Services, Centers for Disease Control and Prevention, National Center for Chronic Disease Prevention and Health Promotion, Office on Smoking and Health.

11. Hayatbakhsh MR, Flenady VJ, Gibbons KS, Kingsbury AM, Hurrion E, et al. (2012) Birth outcomes associated with cannabis use before and during pregnancy. Pediatr Res 71(2): 215-219.

12. Minnes S, Lang A, Singer L (2011) Prenatal Tobacco, marijuana, stimulant, and opiate exposure outcomes and practice implications. Addict Sci Clin Pract 6(1): 57-70.

13. Jaddoe VW, Mackenbach JP, Moll HA, Steegers EA, Tiemeier H, et al. (2006) The Generation R study: design and cohort profile. Euro J Epidemiol 21(6): 475-84.

14. Forrester, MB, Merz RD (2007) Risk of selected birth defects with prenatal illicit drug use, Hawaii, 1986-2002. J Toxicol Environ Health A 70(1): 7-18.

15. Wershak CR, Regan J, Moore B, Magner K, Kritzer S, et al. (2015) Association between Marijuana us and adverse obstetrical and neonatal outcomes. J. Perinatology 35(12): 991-995.

16. van GMM, Reefhuis J, Caton AR, Werler MM, Druschel CM, et al. (2009) National Brith Defects Prevention Study. Maternal periconceptional illicit drug use and the risk of congenital malformations. Epidemiology 20(1): 60-66.
17. Jutras-Aswad D, DiNieri JA, Harkany T, Hurd YL (2009) Neurobiological consequences of maternal cannabis on human fetal development and neuropsychiatric outcome. Eur. Arch Psychiatry Clin Neurosci 259(7): 395-412.

18. Warner TD, Roussos-Ross D, Behnke M (2014) It's Not Your Mother's Marijuana Effects on Maternal-fetal Health and the Developing Child. Clin Perinatol 41(4): 877-894.

19. Day NL, Leech SL, Goldschmidt L (2011) The effects of prenatal marijuana exposure on delinquent behaviors are mediated by measures of neurocognitive functioning. Neurotoxicol Teratol 33(1): 129-136.

20. Fried PA (1995) The Ottawa Prenatal Prospective Study (OPPS): Methodological issues and findings-it's easy to throw the baby out with the bath water. Life Sci 56(23-24): 2159-2168.

21. Day, NL, Richardson GA, Goldschmidt L, Robles N, Taylor PM, et al. (1994) Effect of prenatal marijuana exposure on the cognitive development of offspring at age three. NeurotoxicolTeratol 16(2): 16975.

22. Goldschmidt L, Richardson GA, Willford J, DayNL (2008) Prenatal marijuana exposure and intelligence test performance at age 6. J Am Acad Child Adolesc Psychiatry 47(3): 254-263.

23. Goldschmidt L, Richardson GA, Willford JA, Severtson SG, Day NL, et al. (2012) School achievement in 14-year-old youths prenatally exposed to marijuana. NeurotoxicolTeratol. 34(1): 161-167.

24. Fried PA, Watkinson B, Gray R (2003) Differential effects on cognitive functioning in 13 to 16 -year-olds prenatally exposed to cigarettes and marihuana. NeurotoxicicolTeratol 25(4); 427-436.

25. Marroun HEL, James JH, Tiemeier H, Creemers H, Steegers EAP, et al. (2011) Intrauterine cannabis exposure leads to more aggressive behavior and attention problems in 18-month-old girls. Drug Alcohol Depend 118(2-3): 470-474.

26. Noland JS, Singer LT, Short EJ, Minnes S, Arendt RE, et al. (2005) Prenatal drug exposure and selective attention in preschoolers. Neurotoxicol Teratol, 27(3): 429-438.

27. Goldschmidt L, Day NL, Richardson GA (2000) Effects of prenatal marijuana exposure on child behavior problems at age 10 . NeurotoxicolTeratol 22(3): 325-323.

28. deMoraes BMC, Guinsburg R, de Araújo Peres C, Mitsuhiro S, Chalem E, et al. (2006) Exposure to marijuana during pregnancy alters neurobehavior in the early neonatal period. J Pediatri, 149(6): 781787.

29. Lester BM, Dreher M (1989) Effects of marijuana use during pregnancy on newborn cry. Child Dev 60(4): 765-771.

30. Day, NL, Leech SL, Goldschmidt L (2011) The effects of prenatal marijuana exposure on delinquent behaviors are mediated by measures of neurocognitive functioning. Neurotoxicol Teratol 33(1): 129-136.

31. Fried PA, Watkinson, Siegel LS (1997) Reading and language in 9-to 12year olds prenatally exposed to cigarettes and marijuana. Neuroloxicol Teratol 19(3): 171-183.

32. Djulus J, Moretti M, Koren G (2005) Marijuana use and breastfeeding. Can Fam Physician 51(3): 349-350.

33. Perez-Reyes, M, Wall ME (1982) Presence of delta9tetrahydrocannabinol in human milk. N Engl J Med 307(13): 819-820.

34. Chao FC, Green DE, Forrest IS, Kaplan JN, Winship-Ball A, et al. (1976) The passage of 14C-delta-9-tetrahydrocannabinol into the milk of lactating squirrel monkeys. Res Commun Chem Pathol Pharmacol 15(2): 303-317. 
35. Friguls B, Joya X, Carcia-Algar O, Pallas CR, Vall O, et al. (2010) A comprehensive review of assays methods determine drugs in breast milk and the safety of breastfeeding when taking drugs. Anal Bioanal Chem 397(3): 1157-1179.

36. Liston J (1998) Breastfeeding and the use of recreational drugs-alcohol, caffeine, nicotine and marijuana. Breastfeeding Review 6(2): 27-30.

37. Bennett PN (1997) Cannabis. In: Bennett PN et al. (Eds.), Drugs and human lactation. ( $2^{\text {nd }}$ edn). Elsevier, Amsterdam Holl, USA.

38. Astley SJ, Little RE (1990) Maternal marijuana use during lactation and infant development at one year. Neurotoxicol Teratol 12(2): 161-168.

39. Marijuana Use in Oregon: What we know and what we don't (2014) CD Summary, Oregon Public Health Division 63(12): 1-2.

40. Miller CW (2012) Marijuana Use and Breastfeeding. Clin Lactation 3(3) 102-107.

41. Reece-Stremtan S, Marinelli KA (2015) Guidelines for breastfeeding and substance use or substance use disorder, revised 2015. ABM Clinical Protocol \#21. Academy of Breastfeeding Medicine. Breastfeed Med 10(3): 135-141.

42. Marijuana use during pregnancy and lactation. Committee Opinion No 637. American College of Obstetricians and Gynecologists.Obset. Gynecol 126: 234-238.

43. American Academy of Pediatrics Section on Breastfeeding (2012) Breastfeeding and the use of human milk. Pediatrics 129(3): e827-e841.

44. Federal Drug Aministration. Marinol fact sheet.

45. Cesamet package insert.

46. Nestler EJ (2009) Epigenetic mechanism in psychiatry. Biol Psychiatry 65(3): 189-190.

47. Trezza V, Campolongo P, Cassano T, Macheda T, Dipasquale $P$, Carratu MR, et al. (2008) Effects of perinatal exposure to delta-9tetrahydrocannaboinol on the emotional reactivity of the offspring: a longitudinal behavioral study in Wistar rats. Psychopharmacology (Berl.) 198: 529-537.

48. Morris CV, DiNieri JA, Szutororisz H, Hurd Y (2011) Molecular mechanisms of maternal cannabis and cigarette use on human neurodevelopment. Euro J Neurosci 34(10): 1574-1583.

49. Szutorisz H, DiNieri JA, Sweet E, Egervari G, MichaelidesM, Carter JM, et al. (2014) Parental THC Exposure Leads to Compulsive Heroin-seeking and Altered Striatal Synaptic Plasticity in the Subsequent Generation. Neuropsychopharmacology 39(6): 1315-1323.

50. Ewing CK, Loffredo CA, Beaty TH (1997) Paternal risk factors for isolated membranous ventricular septal defects. Am J Med Genet 71(1): 42-46.

51. Wilson PD, Loffredo CA, Correa-Villasensor A, Ferenez C (1992) Attributable fraction for cardiac malformations. Am J Epidemiol 135: 1394-1403.

52. Monitoring Health Concerns related to legalization of marijuana in Colorado Marijuana in Colorado: 2014, Colorado Department of Public Health \& Environment.
53. Oregon Health Authority, Retail Marijuana Scientific Advisory Committee, Public Health Division.

54. Guidelines for Testing and Report Drug Exposed Newborns in Washington State, Department of Health, USA, pp. 950-951.

55. Sachs HC, Committee on Drugs (2013) The Transfer of Drugs and Therapeutics into Human Breast Milk: An Update on Selected Topics. Clinical Report. Pediatrics 132(3): e796-e809.

56. Fuller T, Wells SJ (2003) Predicting Maltreatment Recurrence among CPS cases with Alcohol and other Drug Involvement. Children and Youth Services Rev 25(7): 553-559.

57. Jaudes PK, Ekwo, E, Van Voohis J (1995) Association of drug abuse and child abuse. Child Abuse Negl 19(9):1065-1075.

58. Ondersman SJ (2002) Predictors of Neglect within Low-SED Families: The importance of substance Abuse. Am J Orthopsychiatry 72: 383391.

59. Freisthler B, Gruenewald PJ, Wolf JP (2015) Examining the relationship between marijuana use, medical marijuana dispensaries, and abusive and neglectful parenting. Child Abuse Negl 48: 170-178.

60. Wang GS, Roosevelt G, Heard K (2013) Pediatric marijuana exposure in a medical marijuana state. JAMA Pediatrics 1657(7): 630-633.

61. Asbridge M, Hayden JA, Cartwright JL (2012) Acute cannabis consumption and motor vehicle collision risk: systematic review of observational studies and meta-analysis. BMJ 344: e536-e539.

62. Brook JS. Balka EB, Fei K, Whiteman M (2006) The Effects of Parental Tobacco and Marijuana Use and Personality Attributes on Child Rearing in African-American and Puerto Rican Young Adults. J Child Fam Stud 15(2): 153-164.

63. Thurstone C, Binswanger IA, Corsi KF, Binehart J, Booth RE (2015) Medical Marijuana Use and Parenting: A Qualitative Study. Adolescent Psychiatry 3(2): 190-194.

64. (2015) The Legalization of Marijuana in Colorado: The Impact. Volume 3 Rocky Mountain High Intensity Drug Trafficking Area. pp. 1-182.

65. Garrard A (2014) Washington Poison Center. Toxic Trends Report.

66. Carstairs SD, Fuinska MK, Keeney GE, Lv BT (2011) Prolonged coma in a child due to hashish ingestion with quantitation of THC metabolites in urine. J Emerg Med 41(3): e69-e71.

67. Wang GS, Lait MC, Deakyne SJ, Bronstein AC, Bajaj L, et al. (2016) Unintentional Pediatric Exposures to Marijuana in Colorado, 20092015. JAMA Pediatr 170(9): 1110-1120.

68. Wilson KM, Torok B, Wei L, Wang M, Robinson CS, et al. (2016) Marijuana Exposure Hospitalized for Bronchiolitis. Pediatric Acad Societies 2016 E-PAS20 16: 4460-4468

69. Colaneri N, Weaver J, Marcus S, Adesman (2016) Change in Adolescents' Perceived Risk of Marijuana Use Following the Legalization of Marijuana in Washington State. Pediatric Acad Societies E-PAS 2016 3880: 720. 
Your next submission with JuniperPublishers will reach you the below assets

- Quality Editorial service

- Swift Peer Review

- Reprints availability

- E-prints Service

- Manuscript Podcast for convenient understanding

- Global attainment for your research

- Manuscript accessibility in different formats ( Pdf, E-pub, Full Text, Audio)

- Unceasing customer service

Track the below URL for one-step submission http://juniperpublishers.com/online-submission.php 